\title{
Response of nematode communities after large-scale ice-shelf collapse events in the Antarctic Larsen area
}

\author{
M. RAES*, A. ROSE $\dagger$ and A. VANREUSEL* \\ *Marine Biology Section, Biology Department, Ghent University, Sterre complex S8, Krijgslaan 281, B-9000 Gent, Belgium, \\ $\dagger$ Department of DZMB, Research Institute Senckenberg (FIS), Südstrand 44, D-26382 Wilhelmshaven, Germany
}

\begin{abstract}
Owing to large-scale ice-shelf disintegration events, the Antarctic Larsen A and B areas recently became ice-free. During the ANT-XXIII/8 Polarstern campaign, this region was sampled for the first time. Our study is the first to investigate benthic communities in this area and their response to the collapse of ice shelves in the Antarctic. The nematofauna appears to be strongly influenced by the sudden ice-cover removal, although its response differs from that of the macro- and megabenthos. Our results indicate that precollapse, sub-ice communities were impoverished and characterized by low densities, low diversity and high dominance of a few taxa. This might still be visible at a station located deep inside the Larsen B embayment, where Halomonhystera was dominant. Post-collapse recolonization of the 'inner' stations, i.e. those located furthermost from the former ice-shelf edge, is believed to be a long-time process. At the time of sampling, community structure at the inner stations was not or only slightly influenced by colonization, and might be structured by local environmental conditions. Our results indicate that a locally increased food supply after ice-cover removal could provoke a faster, local response of the nematode assemblages compared with the response due to recolonization. Thalassomonhystera is recognized as an opportunist, taking advantage of increased food supply at inner stations A_South and B_North. Communities living close to the former ice-shelf edge are believed to be at an intermediate or late stage of succession, with a dominance of Microlaimus, a common Antarctic genus and quick colonizer. Densities here were comparable with those at other Antarctic stations, whereas they were considerably decreased at the inner stations. In general, the collapse of the Larsen ice shelves initially has a positive effect on the shelf nematode fauna in the area, both in terms of abundance and diversity.
\end{abstract}

Keywords: Antarctica, benthos, ice-shelf collapse, Larsen, nematodes

Received 17 April 2009; revised version received 14 August 2009 and accepted 29 August 2009

\section{Introduction}

The Antarctic Peninsula is an area characterized by a rich marine biodiversity, but is also one of the fastest warming areas in the world (King et al., 2003; Chapman \& Walsh, 2007). It is considered one of three areas of recent rapid regional (RRR) warming (Vaughan et al., 2003; Solomon et al., 2007), with a mean annual temperature increase by more than $1.5^{\circ} \mathrm{C}$ since 1950 (19502001) or a mean warming trend of $3.4^{\circ} \mathrm{C}$ per century (Faraday-Vernadsky Station: 1951-2001; Orcadas Station: 1904-1991 and 1993-2001) (Vaughan et al., 2003; Clarke et al., 2007). Some data indicate that warming does not only impact terrestrial or shallow marine communities, as the deeper waters of the Weddell Sea have also warmed during the last 50 years (Weddell Sea Bottom Water, 1989-1995: $0.01{ }^{\circ} \mathrm{C} \mathrm{yr}^{-1}$ ) (Fahrbach et al., 1998; Robertson et al., 2002). Extreme warming near the peninsula was manifestly expressed in 2002, when 500

Correspondence: A. Vanreusel, tel. + 320 92648521, fax +320 92648598, e-mail: ann.vanreusel@ugent.be billion tons or $3250 \mathrm{~km}^{2}$ of ice from the Larsen B ice shelf collapsed at the eastern side of the Antarctic Peninsula, and this in only one month's time (January 31-March 7, 2002) (Fig. 1). A few years before, in 1995, the ice shelf of the nearby Larsen A region had already disintegrated completely. The collapse of the Larsen B ice shelf is unprecedented in its Holocene history, whereas Larsen A had no ice shelf for extended periods during the Holocene (Domack et al., 2005). The Larsen B break-up event is attributed to increased temperatures, culminating in the warmest summer on record for the area and the occurrence of huge melt water pools on the surface of the Larsen B ice shelf in the period immediately before the collapse (Scambos et al., 2000). These exceptional events show the devastating effects global warming can have on the ice shelves of the Antarctic Peninsula.

Marine ecosystems in the Antarctic are becoming increasingly impacted by global warming (Moline et al., 2004; Clarke et al., 2007; Barnes \& Peck, 2008). Our knowledge about the impacts of warming on Antarctic ice shelves and the biota living beneath them 


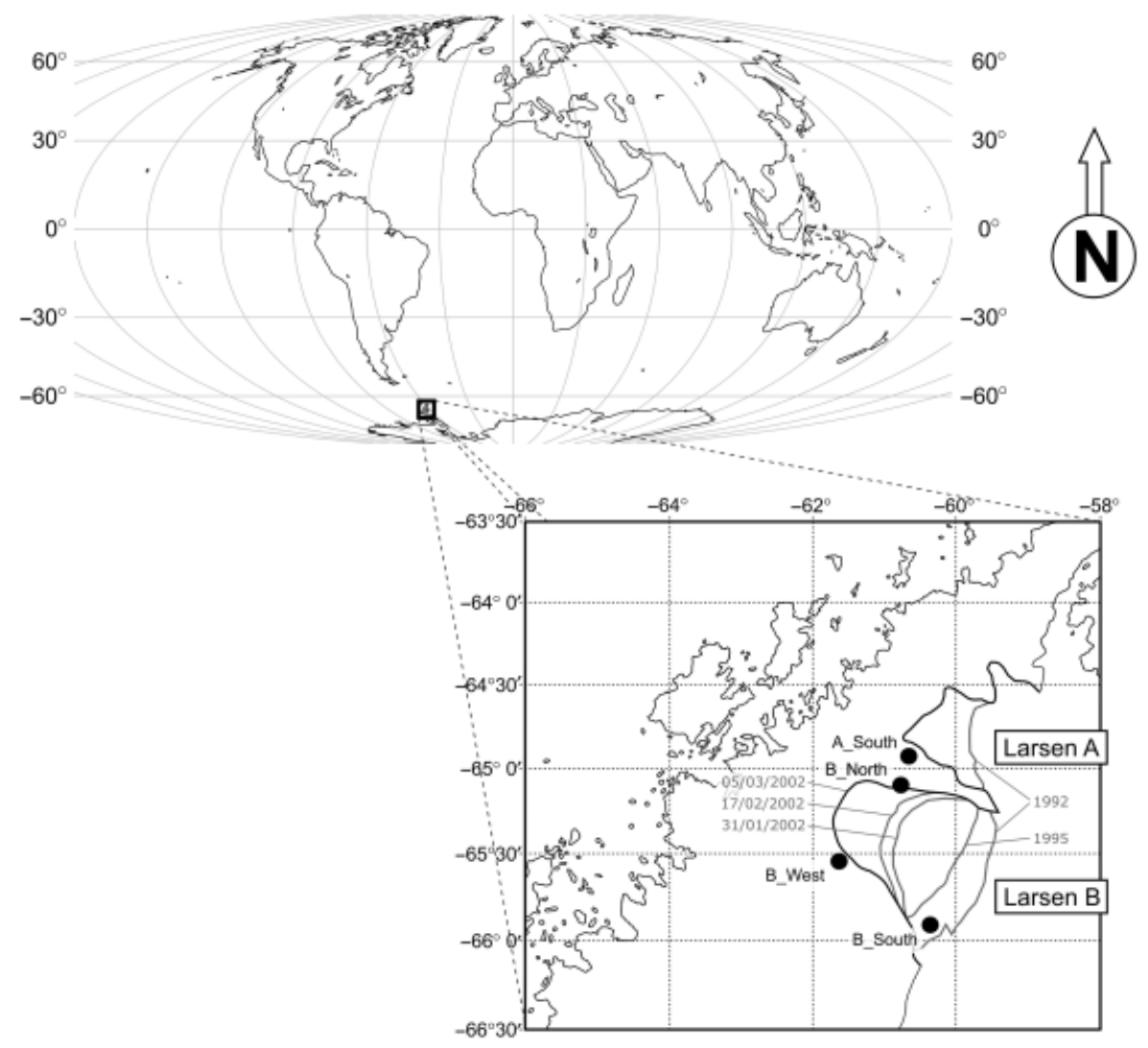

Fig. 1 Map of the study area, with indication of all sampling stations and the maximum ice extent at Larsen A and B between 1992 and March 2002 (Based on BAS, AMM and ESA ERS imagery). The world map is shown in Mollweide projection.

is still limited, although these impacts are already clearly visible and might be far-reaching. Moreover, the nature and biology of the biota underneath ice shelves is also poorly known (Lipps et al., 1979; Hain \& Melles, 1994; Post et al., 2007), although about $34 \%$ of the Antarctic shelf currently lies under ice (Barnes \& Peck, 2008). Ice shelves are known as important indicators of global climate change, as they respond rapidly and acutely to climate warming by increased melting, increased movement and iceberg calving (Scambos et al., 2000). In the past 50 years, regional warming at the Antarctic Peninsula has resulted in the retreat of no less than seven ice shelves (Vaughan \& Doake, 1996; Vaughan et al., 2003). Next to the negative effects of increased iceberg discharge (resulting from ice-shelf collapse) on primary productivity (Arrigo et al., 2002) and the severe destructive effects on benthic communities due to increased iceberg scouring (Peck et al., 1999; Lee et al., 2001), the collapse of large ice shelves also opens up new areas for (benthic) colonization. It should, however, be stressed here that effects of iceberg scouring are not only detrimental, as diversity may increase with increasing rates of iceberg disturbance
(Johst et al., 2006), and increased habitat heterogeneity due to iceberg disturbance may also positively influence regional diversity (Gutt \& Piepenburg, 2003). Between November 23, 2006 and January 30, 2007, the Larsen area was investigated with the German research vessel Polarstern (campaign ANT-XXIII/8). A synoptic approach was applied, including different spatial scales, different groups of organisms (from pelagic to benthic, from primary producers to apex predators) and different environmental characteristics at a limited number of sampling stations (J. Gutt, unpublished results).

The Antarctic continental shelf can be exceptionally rich at local as well as regional spatial scales (Arntz et al., 1994). The collapse of both Larsen ice shelves, distinctly separated in time, could have major consequences for both the ecology and diversity of marine benthic organisms in these areas. Environmental conditions here have obviously changed as a result of the disappearance of an ice cover. Potentially important changes for the benthos include (1) the development of primary production at the water surface (Clarke et al., 2007), (2) an increased frequency of iceberg scouring activity (Gutt, 2001; Gutt \& Piepenburg, 2003), and 
possibly (3) alterations in the flow of bottom currents. Because any information on the benthic biology under the former ice shelves ( $T_{-1}$ situation) is lacking, we will focus in this study on current, ongoing processes and hypothesize about past conditions and their potential effects on the current situation.

Although the precise ecological importance of freeliving marine nematodes is still poorly understood, benthic nematodes, the most abundant group within the marine meiofauna, are known as useful indicators for environmental disturbance and change (Vincx \& Heip, 1991; Schratzberger et al., 2009). Moreover, nematodes are ubiquitous in marine sediments, usually occurring in high densities (Heip et al., 1985), and are very species rich (Lambshead, 2004). Such properties make them ideal test organisms for the impact of retreating ice shelves on the Antarctic benthos.

Our main aims are to investigate the current status of the nematode communities in the Larsen areas, to explain this situation in terms of current and past conditions and to assess the impact of the loss of ice cover in these areas. In this way, we can provide some important insights in the community response of benthic biota at the Antarctic Peninsula to future warming. Community level responses to climate-change related impacts are at present poorly known (Clarke et al., 2007), and this study increases our knowledge at this level.

Our initial hypothesis was that after ice-shelf collapse, the nematode communities would have become denser and more diverse through a combination of increased food supply and colonization from the open Weddell Sea. We expected the communities deep inside the Larsen area to be at an intermediate stage of succession.

\section{Material and methods}

\section{Material and area of investigation}

The Larsen area consists of three embayments located to the east of the Antarctic Peninsula: the small Larsen A area in the north, the large Larsen $C$ area in the south and Larsen B in between both areas. Larsen $\mathrm{A}$ is situated immediately north of Larsen B; both areas are separated by a narrow strip probably consisting of ice and some islands. Following a synoptic approach, which focuses on the integration of diverse biological data from a limited number of stations, sampling for nematodes was carried out at three stations in Larsen B (Larsen B_South, Larsen B_West and Larsen B_North) and one station in Larsen A (Larsen A_South) (Fig. 1, Table 1). Samples were taken at depths between 229 and $427 \mathrm{~m}$ (Table 1).

Based on ice cover images originating from different sources [British Antarctic Survey (BAS); Antarctic Mapping Mission (AMM); European Space Agency's Euro-pean Remote Sensing Satellite (ESA ERS)], we were able to put together a composite schematic depicting the ice collapse sequence between 1992 and 2002 (Fig. 1). This image shows us that our sampling stations have been free of ice-cover for different periods of time: the area of station B_South has been ice-free at least since 1995 (Larsen A collapse), the area of station B_North probably became ice-free in 2002 (Larsen B collapse) and the other two stations became free of ice cover somewhere between 2002 and 2007 (time of sampling). Note that, judging from this figure, stations B_West and A_South were still completely ice-covered after 05/03/2002, whereas station B_North was situated near the shelf edge at that time.

Table 1 Sampling sites: all replicate drops are listed with date of deployment, coordinates and depth of sampling

\begin{tabular}{llllll}
\hline Station & Deployment & Date & Latitude & Longitude & Depth (m) \\
\hline Larsen B_South & PS69/700-8 & 11.01 .2007 & $65^{\circ} 54.98^{\prime} \mathrm{S}$ & $60^{\circ} 20.54^{\prime} \mathrm{W}$ & 422 \\
Larsen B_South & PS69/700-9 & 11.01 .2007 & $65^{\circ} 54.95^{\prime} \mathrm{S}$ & $60^{\circ} 20.88^{\prime} \mathrm{W}$ & 417 \\
Larsen B_South & PS69/702-4 & 12.01 .2007 & $65^{\circ} 55.12^{\prime} \mathrm{S}$ & $60^{\circ} 19.96^{\prime} \mathrm{W}$ & 427 \\
Larsen B_South & PS69/702-7 & 12.01 .2007 & $65^{\circ} 54.49^{\prime} \mathrm{S}$ & $60^{\circ} 21.37^{\prime} \mathrm{W}$ & 405 \\
Larsen B_South & PS69/702-8 & 12.01 .2007 & $65^{\circ} 54.95^{\prime} \mathrm{S}$ & $60^{\circ} 20.95^{\prime} \mathrm{W}$ & 410 \\
Larsen B_West & PS69/710-2 & 16.01 .2007 & $65^{\circ} 33.03^{\prime} \mathrm{S}$ & $61^{\circ} 36.98^{\prime} \mathrm{W}$ & 277 \\
Larsen B_West & PS69/710-3 & 16.01 .2007 & $65^{\circ} 33.04^{\prime} \mathrm{S}$ & $61^{\circ} 37.18^{\prime} \mathrm{W}$ & 281 \\
Larsen B_West & PS69/710-7 & 16.01 .2007 & $65^{\circ} 33.03^{\prime} \mathrm{S}$ & $61^{\circ} 37.01^{\prime} \mathrm{W}$ & 275 \\
Larsen B_West & PS69/710-8 & 16.01 .2007 & $65^{\circ} 33.03^{\prime} \mathrm{S}$ & $61^{\circ} 37.00^{\prime} \mathrm{W}$ & 283 \\
Larsen B_West & PS69/710-9 & 16.01 .2007 & $65^{\circ} 33.07^{\prime} \mathrm{S}$ & $61^{\circ} 37.06^{\prime} \mathrm{W}$ & 288 \\
Larsen B_North & PS69/715-2 & 18.01 .2007 & $65^{\circ} 6.39^{\prime} \mathrm{S}$ & $60^{\circ} 45.04^{\prime} \mathrm{W}$ & 308 \\
Larsen B_North & PS69/715-4 & 18.01 .2007 & $65^{\circ} 6.44^{\prime} \mathrm{S}$ & $60^{\circ} 45.07^{\prime} \mathrm{W}$ & 307 \\
Larsen B_North & PS69/718-1 & 19.01 .2007 & $65^{\circ} 6.33^{\prime} \mathrm{S}$ & $60^{\circ} 45.17^{\prime} \mathrm{W}$ & 306 \\
Larsen B_North & PS69/718-3 & 19.01 .2007 & $65^{\circ} 6.43^{\prime} \mathrm{S}$ & $60^{\circ} 44.93^{\prime} \mathrm{W}$ & 303 \\
Larsen B_North & PS69/718-5 & 19.01 .2007 & $65^{\circ} 6.40^{\prime} \mathrm{S}$ & $60^{\circ} 45.60^{\prime} \mathrm{W}$ & $60^{\circ} 38.57^{\prime} \mathrm{W}$ \\
Larsen A_South & PS69/723-1 & 22.01 .2007 & $64^{\circ} 56.07^{\prime} \mathrm{S}$ & $60^{\circ} 38.58^{\prime} \mathrm{W}$ & 242 \\
Larsen A_South & PS69/723-2 & 22.01 .2007 & $64^{\circ} 56.06^{\prime} \mathrm{S}$ & 242 \\
\hline
\end{tabular}


Nematodes were collected using a multicorer, a device able to take a maximum of 12 undisturbed sediment cores per drop. Each core had an inner diameter of $57 \mathrm{~mm}\left(25.52 \mathrm{~cm}^{2}\right)$. Five replicate deployments were successful at Larsen B_South, B_West and B_North; for Larsen A_South only two deployments could be processed. From each deployment, one core was subdivided in sediment slices of $1 \mathrm{~cm}(0-1 ; 1-2 ; 2-3 ; 3-4$; $4-5 \mathrm{~cm}$ ) for community analysis. Each slice was fixed separately with $4 \%$ buffered formalin. Parallel cores from the same MUC deployment were sliced in the same way and frozen at $-20^{\circ} \mathrm{C}$ for grain size and pigment analysis.

\section{Laboratory analyses}

The meiofauna fraction was separated from the macrofauna fraction with a $1 \mathrm{~mm}$ and $32 \mu \mathrm{m}$ sieve. Meiofauna was extracted from the sediment by density gradient centrifugation, with Ludox HS-40 as a flotation medium (Heip et al., 1985; Vincx, 1996), and stained with Rose Bengal. From each core, 200 nematodes were picked out randomly: the number of individuals to be picked out per slice was determined by the percentual partition of total nematode counts over all slices. Nematode specimens were mounted onto slides using the formalin-ethanol-glycerol technique of Seinhorst (1959) and Vincx (1996), and identified up to genus level using the identification key of Warwick et al. (1998) and original genus descriptions.

Grain size analysis was carried out using laser diffraction (Malvern Mastersizer 2000, Malvern Instruments, Worcestershire, UK). The following grain size variables were considered in this study: volume weighted mean; clay \%; silt \%; very fine sand $\%$; fine sand $\%$; medium sand $\%$; coarse sand $\%$; volume weighted mean in upper $\mathrm{cm}$; clay $\%$ in upper $\mathrm{cm}$; silt $\%$ in upper $\mathrm{cm}$; very fine sand $\%$ in upper $\mathrm{cm}$; fine sand $\%$ in upper $\mathrm{cm}$; medium sand $\%$ in upper $\mathrm{cm}$ and coarse sand $\%$ in upper $\mathrm{cm}$.

Photopigment concentration was measured by high-performance liquid chromatography (HPLC) analysis of the supernatant (extracted from the lyophilized sediment by adding $10 \mathrm{~mL} \mathrm{90 \%} \mathrm{acetone).} \mathrm{The} \mathrm{following} \mathrm{pigment} \mathrm{variables} \mathrm{were}$ considered in this study: $\mu \mathrm{g} \mathrm{g}^{-1} \mathrm{chl} a ; \mu \mathrm{g} \mathrm{g}^{-1} \mathrm{CPE}$ (chloroplastic pigment equivalents); ${\mu \mathrm{gg}^{-1}}$ phaeopigments; $\mu \mathrm{gg}^{-1} \mathrm{chl} a$ in upper $\mathrm{cm} ; \mu \mathrm{g} \mathrm{g}^{-1} \mathrm{CPE}$ in upper $\mathrm{cm} ; \mu \mathrm{g} \mathrm{g}^{-1}$ phaeopigments in upper $\mathrm{cm}$.

\section{Statistical analyses}

Bray-Curtis (dis)similarities between samplings were calculated using the PRIMER v5 software (Plymouth Marine Laboratory; Clarke \& Gorley, 2001). The obtained similarity matrix was used to produce a non-metric multidimensional scaling two-dimensional plot (nMDS) and a cluster dendrogram (group average), and to perform a one-way or two-way crossed Analysis of Similarities (ANOSIM test). The stress value of an nMDS biplot gives a measure for goodness-of-fit of the nMDS ordination; a low stress value $(<0.1)$ corresponds to a good ordination with no real prospect for a misleading interpretation (Clarke \& Warwick, 2001). A Similarities of Percentages (SIMPER) analysis was performed to investigate which genera were responsible for the observed dissimilarities. All former analyses were carried out on square-root transformed abundance data, except for the two-way ANOSIM analysis, which was performed with $\log (x+1)$ transformed relative data.

The assignment of trophic groups was based on the classification by Wieser (1953).

The PRIMER v5 software was also used to calculate a range of biodiversity indices: Hill's numbers $N_{0}, N_{1}$ and $N_{\text {inf }}$ (Hill, 1973), the expected number of genera (an index based on the expected number of species after the rarefaction algorithm of Hurlbert (1971)) for a sample of 200 individuals EG (200), the Shannon-Wiener index $H^{\prime}$, Pielou's evenness $J^{\prime}$, and several diversity indices based on relatedness of species (here adapted for genera): average taxonomic distinctness $\Delta^{*}$ (with abundance information), as well as the qualitative $\Delta^{+}$and the corresponding variation in taxonomic distinctness $\Lambda^{+}$(both presence-absence). Average taxonomic distinctness reflects the mean path length through the taxonomic tree connecting every pair of genera in the list, whereas variation in taxonomic distinctness reflects the variance of these pairwise path lengths and reflects the unevenness of the taxonomic tree (Warwick \& Clarke, 2001). The weights given to the branch lengths in the taxonomic tree depend on the taxon richness of the master list. The master list used for this analysis was constructed to be representative for the Antarctic marine nematode community (very shallow areas excluded) and was comprised of data from the Larsen area (present study), the Drake Passage, Halley Bay, Kapp Norvegia, the South Sandwich Islands, Vestkapp and the Weddell Sea Abyssal Plain (Vanhove et al., 1999; Ingels et al., 2006; Sebastian et al., 2007). This list included 269 genera and eight taxonomic levels (genus, family, superfamily, subordo, ordo, subclassis, classis and phylum). Probability funnels were used to check whether our stations had a higher or lower than expected taxonomic spread, assuming a null hypothesis that each sample is a random selection from the regional genus pool (Warwick \& Clarke, 2001). The TAXDTEST routine was used to test this null hypothesis. For the construction of a $95 \%$ probability funnel, the values for each of the stations (pooled data) were plotted against a continuously changing number of genera, together with the values for 5000 random selections from the master list (funnel: $95 \%$ probability interval) and the simulated mean of the master list values (dashed line). TAXDTEST and the probability funnels were also computed with the PRIMER v5 software.

An Indicator Species Analysis (adapted for genera) on square-root transformed abundance data was carried out with the PC-ORD4 software (McCune \& Mefford, 1999). Statistical significance of maximal indicator values $\left(\mathrm{IV}_{\max }\right)$ was tested using a Monte Carlo test (Dufrêne \& Legendre, 1997).

Non-parametric (Mann-Whitney $U$-test by ranks) analysis of variance was performed with the STATISTICA6 software to test for significant differences in abundances between stations and sediment layers, significant differences in diversity indices between stations and significant differences in environmental variables between stations. Shapiro-Wilk's $W$-test was used to test for normality in the dataset. Bartlett's $\chi^{2}$-tests were used to verify the homogeneity of variances. Assumptions were tested before the analysis. 
A principal components analysis (PCA) and the BIO-ENV procedure (PRIMER v5) was carried out with the $\log (x+0.1)$ transformed datasheet of environmental factors and the sqrttransformed biological similarity matrix, in order to calculate a measure of agreement between both matrices (Clarke \& Gorley, 2001) by investigating which combination of the environmental variables best matches the biological patterns emerging from the similarity matrix.

\section{Results}

\section{Community: structure and diversity}

Average nematode densities differed greatly between stations; they were significantly lower at stations A_South $\left(563.38 \pm 244.04 \mathrm{ind} / 10 \mathrm{~cm}^{2}\right)$ and B_West $\left(606.00 \pm 141.48 \mathrm{ind} / 10 \mathrm{~cm}^{2}\right) \quad$ (Mann-Whitney $\bar{U}$-test; $\mathrm{df}=1 ; \quad P \leq 0.001)$, intermediate at Larsen B_North $\left(1552.51 \pm 327.45 \mathrm{ind} / 10 \mathrm{~cm}^{2}\right)$ and significantly higher at Larsen B_South $\left(3079.86 \pm 531.80 \mathrm{ind} / 10 \mathrm{~cm}^{2}\right)$ (MannWhitney $U$-test; $\mathrm{df}=1 ; P=0.0012$ ).

A total of 3831 nematode specimens was identified, yielding 80 genera. An overview of the dominant genera at each station (relative abundance $>1 \%$ ) is provided in Table 2. Microlaimus was the dominant genus at B_South, whereas the other stations were dominated by the closely related genera Halomonhystera and Thalassomonhystera. In contrast to stations B_North and A_South, which were dominated by Thalassomonhystera, B_West was dominated by Halomonhystera. The communities at B_North and A_South were dominated by the same four genera: besides the aforementioned genera also Neochromadora and Prochromadorella. The dominance of Thalassomonhystera was much higher at Larsen B_North (57.28\% vs. $27.82 \%$ at A_South).

Overall, nematode community structure was significantly different at all stations (Fig. 2a). All stations are well separated (one-way ANOSIM; overall $R=0.994$ and $P=0.001 ; R=1$ for all pairwise comparisons). Judging from the cluster dendrogram (Fig. 2b), the samplings from stations A_South and B_North are most similar to each other, and those from B_South are most different from the other samplings. This is confirmed by the calculated pairwise dissimilarity values: lowest between A_South and B_North (43.56), and highest between B_South and B_West (63.79). The dissimilarity between the latter two stations was mainly attributed to the absence of Microlaimus at B_West (explains $12.14 \%$ of dissimilarity) and the much higher relative abundance of Halomonhystera at this station (explains $10.59 \%$ ). This agrees well with the dominance patterns at these stations (Table 2). Microlaimus was the most important genus to explain the average similarity between the B_South samplings (explains 17.68\%). Average similarity (1) between B_North samplings was mainly explained by Thalassomonhystera (explains $37.79 \%$ ), Halomonhystera (explains $23.08 \%$ ) and Neochromadora (explains 11.17\%), (2) between A_South samplings by Halomonhystera (explains 15.82\%), Thalassomonhystera (explains 14.95\%) and Neochromadora (explains 10.57\%), and (3) between B_West samplings by Halomonhystera (explains $36.98 \%$ ), and Thalassomon-

Table 2 Relative abundance of dominant genera per station (relative abundance $>1 \%$ )

\begin{tabular}{|c|c|c|c|c|c|c|c|}
\hline \multicolumn{2}{|l|}{ Larsen B_South } & \multicolumn{2}{|l|}{ Larsen B_North } & \multicolumn{2}{|l|}{ Larsen B_West } & \multicolumn{2}{|l|}{ Larsen A_South } \\
\hline Genus & $\%$ & Genus & $\%$ & Genus & $\%$ & Genus & $\%$ \\
\hline Microlaimus & 32.20 & Thalassomonhystera & 57.28 & Halomonhystera & 57.88 & Thalassomonhystera & 27.82 \\
\hline Metadesmolaimus & 10.98 & Halomonhystera & 23.34 & Thalassomonhystera & 21.00 & Halomonhystera & 21.94 \\
\hline Paracanthonchus & 9.90 & Neochromadora & 6.08 & Theristus & 3.83 & Neochromadora & 9.76 \\
\hline Halomonhystera & 9.09 & Prochromadorella & 3.09 & Acantholaimus & 3.17 & Prochromadorella & 6.18 \\
\hline Monhystrella & 4.23 & Metadesmolaimus & 2.51 & Daptonema & 2.28 & Procamacolaimus & 4.19 \\
\hline Neochromadora & 3.11 & Elzalia & 1.77 & Monhystrella & 1.97 & Paracanthonchus & 3.76 \\
\hline Prochromadorella & 3.09 & Acantholaimus & 1.13 & Desmodorella & 1.83 & Theristus & 3.76 \\
\hline Araeolaimus & 3.07 & Theristus & 1.04 & Halalaimus & 1.19 & Acantholaimus & 2.66 \\
\hline Acantholaimus & 2.78 & & & & & Araeolaimus & 2.23 \\
\hline Thalassomonhystera & 2.35 & & & & & Microlaimus & 2.01 \\
\hline Theristus & 2.00 & & & & & Innocuonema & 1.97 \\
\hline Leptolaimus & 1.87 & & & & & Monhystrella & 1.56 \\
\hline Elzalia & 1.42 & & & & & & \\
\hline Daptonema & 1.33 & & & & & & \\
\hline Desmodorella & 1.30 & & & & & & \\
\hline Halichoanolaimus & 1.27 & & & & & & \\
\hline Dichromadora & 1.18 & & & & & & \\
\hline Desmodora & 1.10 & & & & & & \\
\hline
\end{tabular}


hystera (explains 20.79\%) (SIMPER analysis). An indicator species analysis revealed significant $(P \leq 0.001)$ maximal indicator values of Microlaimus $\left(\mathrm{IV}_{\max }=81.5\right)$ and Metadesmolaimus ( $\left.\mathrm{IV}_{\max }=54.2\right)$ for station B_South, and of Halomonhystera ( $\mathrm{IV}_{\max }=38.9$ ) for station B_West.

Nonselective deposit feeders dominated all stations (56.30-88.74\%), except for station B_South, which was dominated by epistratum feeders (Wieser 2a: 57.70\%). The prevalence of epistratum feeders at Larsen B_South (in contrast to the other stations) was mainly attributed to Microlaimus $\left(P=0.001 ; \quad \mathrm{IV}_{\max }=96.4\right)$ and Paracanthonchus $\left(P=0.001 ; \mathrm{IV}_{\max }=90.6\right)$.

A two-way crossed ANOSIM analysis of all depth layers in the sediment, taking into account the potential effects of both stations and depth layers, confirmed that all stations can be clearly separated from each other (overall $R=0.719$ ). Moreover, the $0-1 \mathrm{~cm}$ layer could easily be separated from the other layers: $1-2 \mathrm{~cm}$ ( $R=0.647), 2-3 \mathrm{~cm}(R=0.875), 3-4 \mathrm{~cm}(R=0.792)$ and $4-5 \mathrm{~cm}(R=0.869)$. The genus composition of the upper layer was comparable with that of the entire depth profile, except for station B_West, where the upper cm was dominated by Thalassomonhystera $(33.81 \%)$ instead
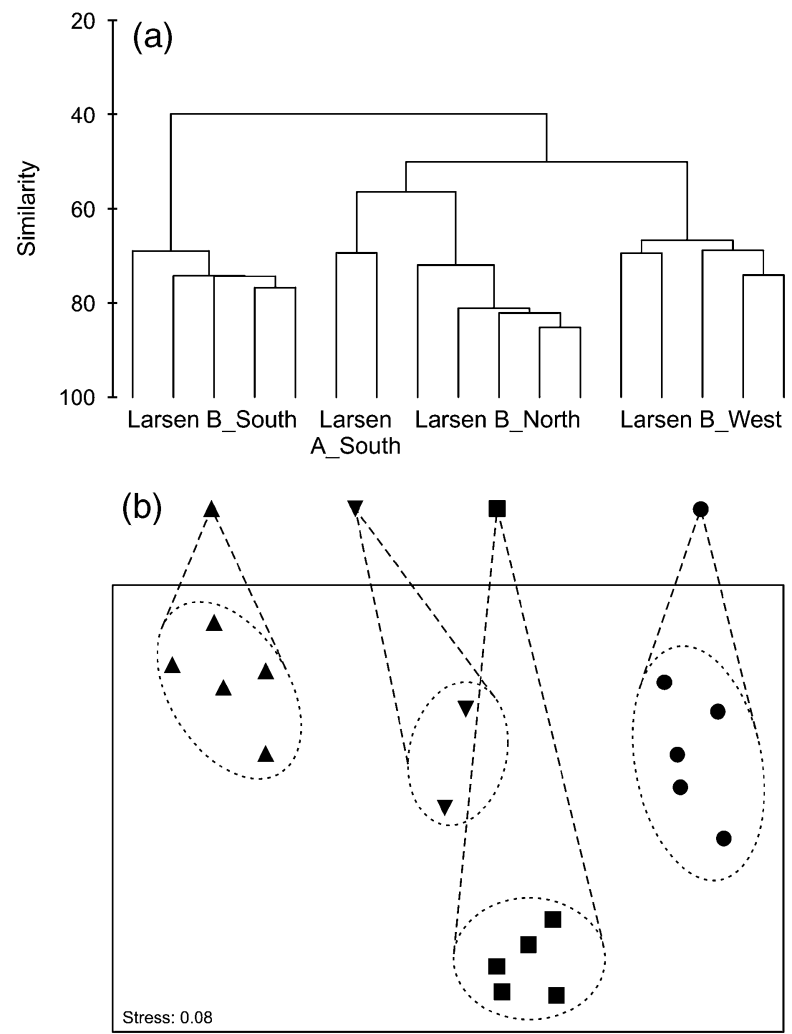

Fig. 2 Multivariate community analysis. (a) Cluster dendrogram (group average); (b) non-metric multidimensional scaling biplot. of Halomonhystera, which was, however, by far the most abundant genus in the deeper sediment layers (relative abundance: $85.24 \%$ ). Halomonhystera was also much more abundant in the deeper layers at station Larsen B_South $(22.82 \%)$, compared with the upper $\mathrm{cm}$ where the genus accounted for only $0.54 \%$ of the community. Overall, the relative abundance of Halomonhystera in the first $\mathrm{cm}(17.59 \pm 14.15 \%)$ was lower than in the deeper sediment layers $(42.89 \pm 29.36 \%)$, although standard deviation is quite high. Nevertheless, the higher abundance of this genus in the deeper sediment layers was statistically significant (Mann-Whitney $U$-test; $d f=1$; $P=0.0068$ ).

The total number of genera was highest at Larsen B_South (49) and lowest at Larsen B_North (24). Even though only half the number of individuals was identified at Larsen A_South, the station still yielded 38 genera. In comparison, the expected number of genera for 451 individuals (i.e. the no. of individuals at station A_South) is 37 at station B_South and 18 at station B_North, respectively. The average values of genus richness $N_{0}$, the expected number of genera EG (200), the Shannon Wiener index $H^{\prime}$ and Hill's $N_{1}$ all followed the same trend: highest values for B_South and A_South, and lowest values for B_North (Fig. 3). In contrast, evenness $\left(N_{\text {inf }}, J^{\prime}\right)$ was lower at B_West compared with B_North.

Highest values of average taxonomic distinctness with abundance data $\left(\Delta^{*}\right)$ were calculated for stations B_South and A_South, whereas stations B_North and B_West yielded significantly (Mann-Whitney $U$-test; $\mathrm{df}=1 ; P \leq 0.001$ ) lower average values (Fig. 4). When working with presence-absence data $\left(\Delta^{+}\right)$, values were more similar to each other, although with a slightly (not statistically significant) lower value at station B_North. In contrast, average values for variation in taxonomic distinctness $\left(\lambda^{+}\right)$were highest at B_North, and lowest at B_South (Mann-Whitney $U$-test; $\mathrm{df}=1 ; P=0.045$ ). Although the average $\Lambda^{+}$values were not significantly higher at station B_North, the $\Lambda^{+}$value for the pooled data at this station plots above the $95 \%$ probability funnel (Fig. 5). A deviation from the null hypothesis (random selection from the regional genus pool) for this station was confirmed by a TAXDTEST analysis $(P=0.032)$.

\section{Community: correlations with environmental factors}

Highest pigment concentrations were found at stations B_North and A_South $(0.46 \pm 0.17$ and $0.43 \pm$ $0.19 \mathrm{\mu g} \mathrm{g}^{-1}$, respectively); lowest concentrations were present at station B_West $\left(0.32 \pm 0.09 \mu \mathrm{g} \mathrm{g}^{-1}\right)$ (Fig. 6). Differences were not statistically significant (MannWhitney $U$-test: $\mathrm{df}=1, P \geq 0.05)$. At the latter station, 
almost all pigments were concentrated in the upper $\mathrm{cm}$ $(97.38 \pm 5.25 \%)$. The contribution of phaeopigments was comparable at most stations (22.52 \pm 9.93 $37.58 \pm 8.15$ ), except for Larsen A_South, where it was significantly lower $(2.87 \pm 4.06 \%$; Mann-Whitney $U$ test: $\mathrm{df}=1, P=0.03$ ).

Mean grain size ranged from $10.03 \pm 1.63 \mu \mathrm{m}$ at station B_West (significantly lower than at the other stations: MannWhitney $U$-test; $\mathrm{df}=1 ; P=0.002)$ up to $64.25 \pm 19.72 \mu \mathrm{m}$ at station A_South (significantly higher than at the other stations: MannWhitney $U$-test; $\mathrm{df}=1$; $P=0.03$ ) (Fig. 7). Only at station B_South, the mean grain size in the upper $\mathrm{cm}$ was significantly different (i.e. higher) from the mean of the entire sediment core (Mann-Whitney $U$-test; $\mathrm{df}=1 ; P=0.05$ ). The pellite (clay + silt) fraction was significantly lower at station A_South (Mann-Whitney $U$-test; $\mathrm{df}=1 ; P=0.03$ ); the other fractions (very fine sand, fine sand, medium sand, coarse sand) were significantly higher at this station (Mann-Whitney $U$-test; $\mathrm{df}=1 ; P=0.03$ for all fractions).

A BIO-ENV procedure revealed that the environmental variables we considered did not match in any combination the biological patterns emerging from the nMDS (correlation 0.056).
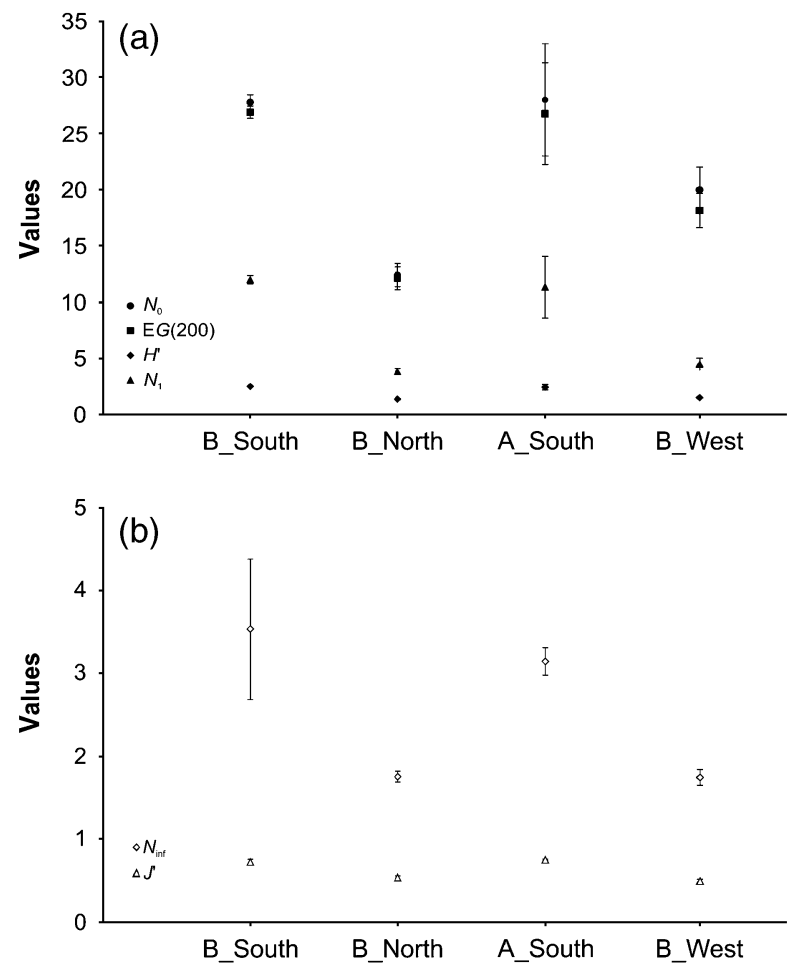

Fig. 3 An overview of key biodiversity indices for the four Larsen stations (average with standard error flags). (a) $N_{0}$, EG (200), $H^{\prime}, N_{1}$; (b) evenness $\left(N_{\text {inf }}, J^{\prime}\right)$.

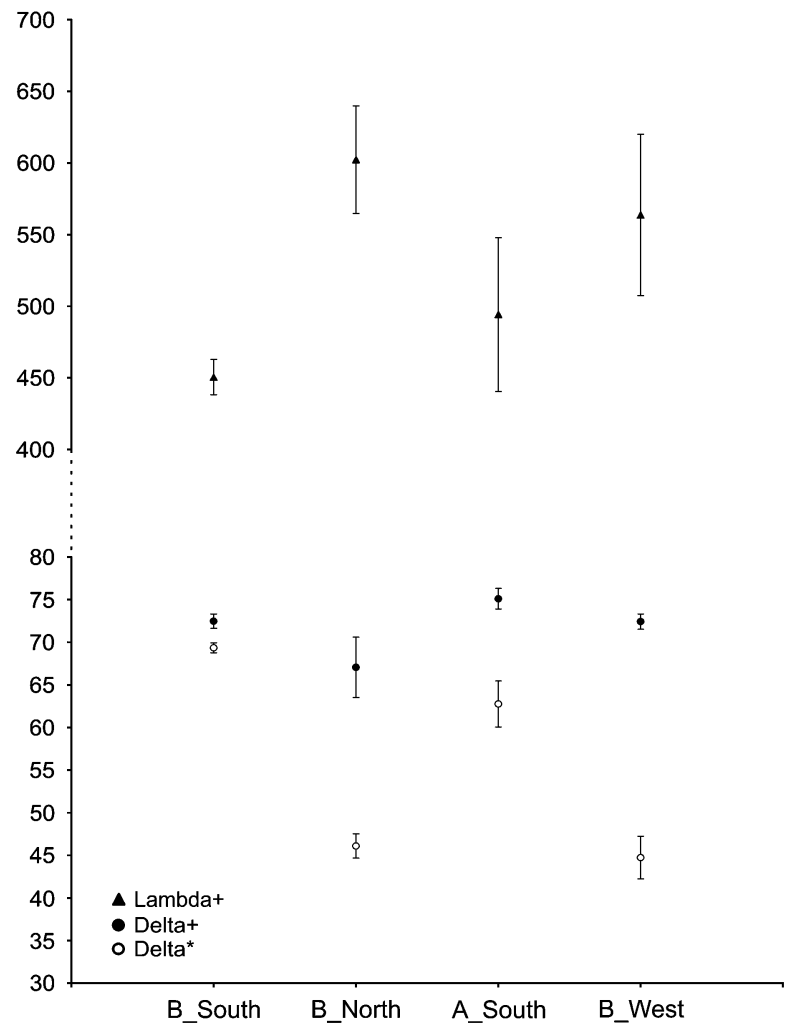

Fig. 4 Biodiversity indices based on relatedness of species, calculated for all Larsen stations (average with standard error flags).

\section{Discussion}

Community results suggest a classification of the investigated stations in three groups: (1) station B_South, dominated by Microlaimus; (2) stations B_North and A_South, dominated by Thalassomonhystera and (3) station B_West, dominated by Halomonhystera. Station B_South was most dissimilar from the other stations (cf. cluster dendrogram), and especially from station B_West.

As B_South, situated closest to the open Weddell Sea, is the only station free of ice cover before the Larsen B ice shelf collapse in 2002, it is regarded here as a reference site for the impacts of the Larsen ice-shelf collapse. All other stations are located deeper inside the Larsen embayments and even the Larsen A station was ice-covered at least until 2002. Hereafter, these stations are referred to as the inner stations, and B South as the outer station. The geographical position of the stations appears to match the aforementioned classification: the outer station B_South, station B_West located deepest inside the Larsen $B$ area and the two northern stations B_North and A_South. However, this classification does not follow the obvious distinction between the two embayments Larsen A and B. On the other hand, faunal 


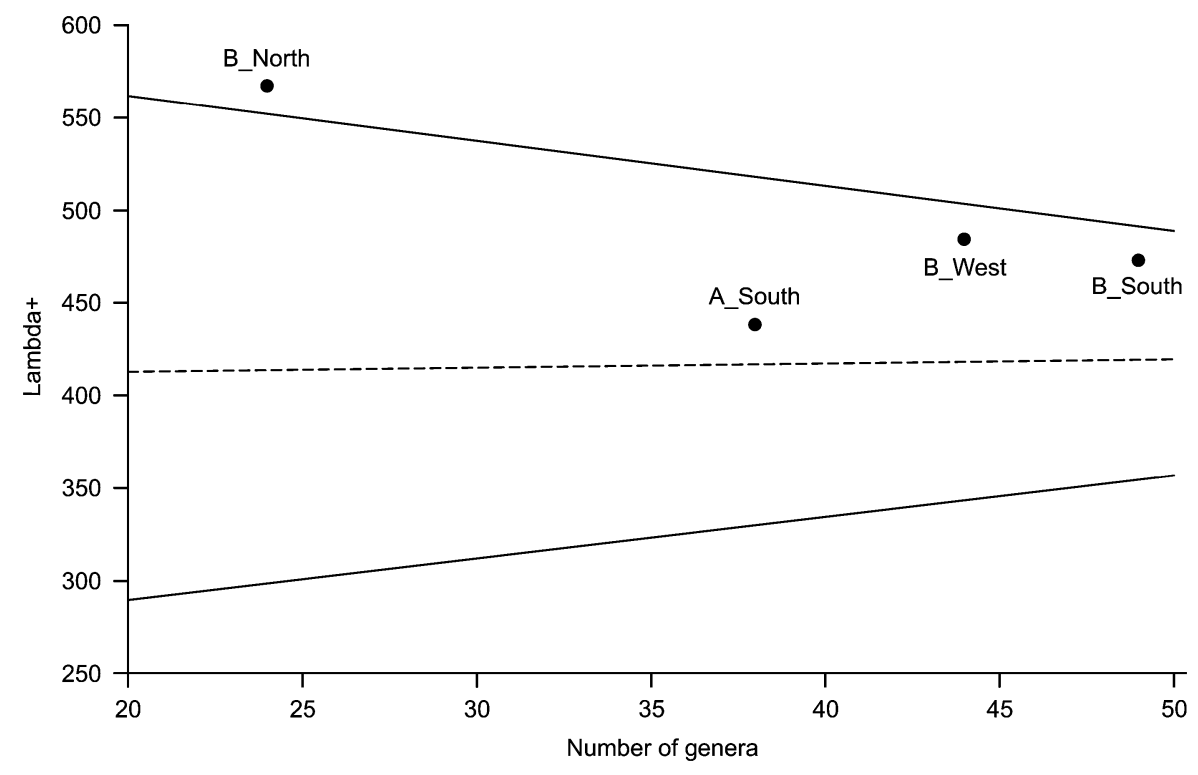

Fig. 5 95\% probability funnel (full line) and simulated mean (dashed line) for the variation in taxonomic distinctness diversity index. The values for the four stations are plotted against $N_{0}$.

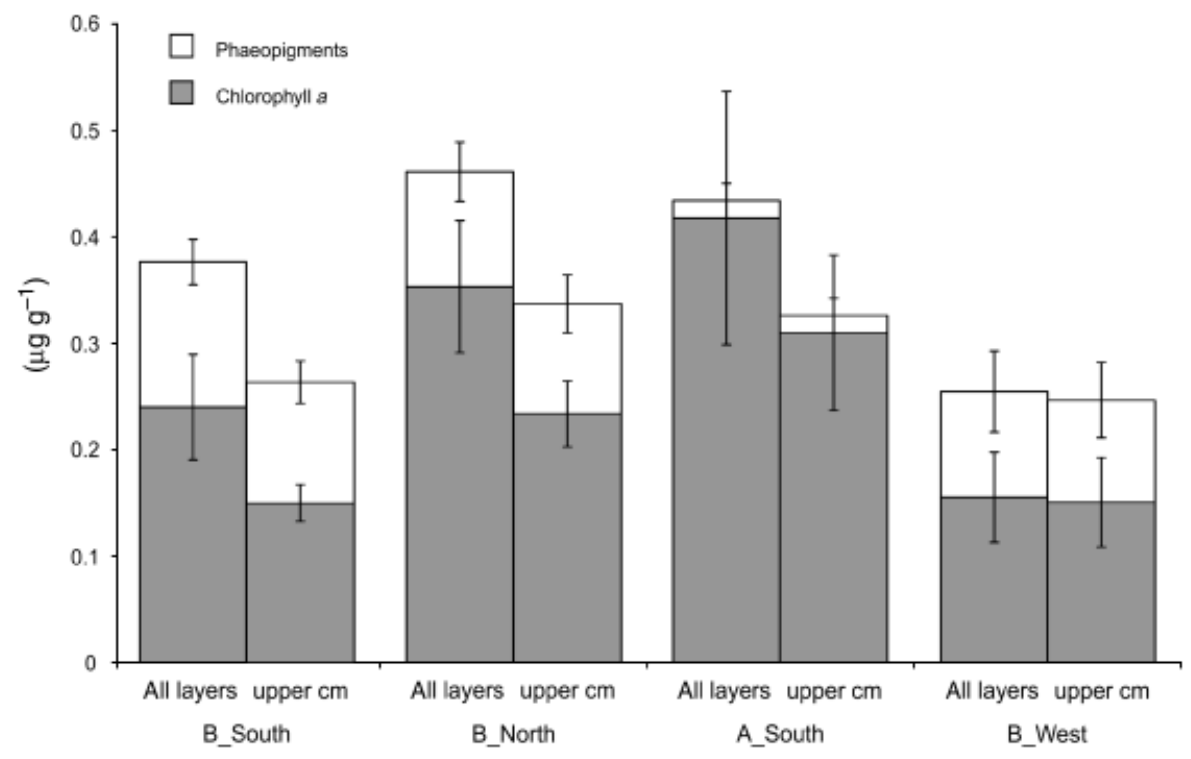

Fig. 6 Pigment content in the sediment at the Larsen stations (average values + standard error): chlorophyll $a$, phaeopigments and CPE ( = chlorophyll $a+$ phaeopigments). Values are given for the entire sediment column and the upper cm separately.

exchange between Larsen A and B could be possible if the ice-covered strip separating both areas at least partly consists of floating ice.

Three factors related to ice coverage could have had an influence on the investigated nematode communities: (1) length of the period free of shelf-ice cover, (2) distance to a (rich) source of nematodes for colonization and (3) primary production in the water column above the stations. Other environmental factors, such as sediment granulometry, could also have played a role here. Relevant community features at the investigated stations are summarized in Table 3 .

Food availability is a major structuring factor for meiobenthic populations and communities (Vanhove et al., 2000), and nematodes are especially sensitive to changes in the availability of organic food (Fabiano \& Danovaro, 1999; Gutzmann et al., 2004). Oligotrophic conditions negatively affect meiobenthic and nematode abundance (Vincx et al., 1994; Vanreusel et al., 2000). In general, low temperatures and low microbial activity in 


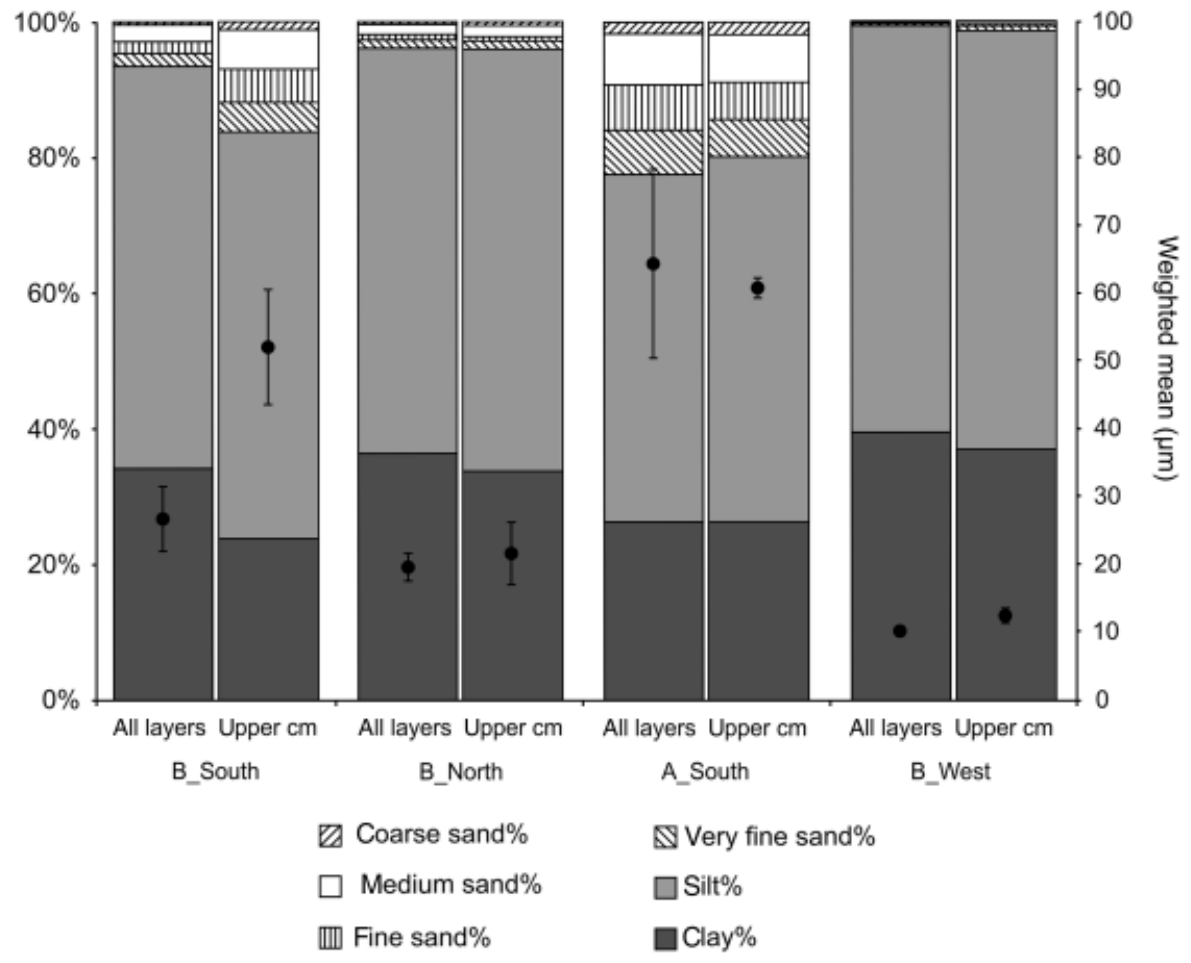

Fig. 7 Granulometric composition (bars) and volume weighted mean (average + standard error) of the sediment at the Larsen stations, both for the entire sediment column and the upper $\mathrm{cm}$.

the Antarctic result in low organic degradation rates (Bathmann et al., 1991) and, hence, accumulation of fresh organic matter in the sediment, resulting in a high meiobenthic standing stock (Vanhove et al., 1995; Fabiano \& Danovaro, 1999). Extensive and long-term ice cover impedes or, in case of sea ice persisting only for weeks or months, delays phytoplankton production, in this way severely impacting the entire pelagic (Arrigo et al., 2002) and benthic ecosystem. Still, the ocean floor underneath large ice shelves is not a desert, devoid of life. According to Oliver et al. (1976), Riddle et al. (2007) and Post et al. (2007), sub-ice benthic communities can be diverse and abundant. The seafloor beneath large ice shelves is open to colonization from the open water, although the colonization process of the ice-covered seafloor by benthic organisms is a very slow process, taking up to $10^{3}$ year (Post et al., 2007). Slow succession rates underneath the ice are probably related to the long dispersal distance between source and sink, and the low food supply to the sub-ice shelf communities. This implies that ice-shelf collapse only accelerates the speed of colonization of the seafloor.

The low number of iceberg scour marks $(4.2 \%$ of seafloor) and the presence of slow-growing hexactinellid sponges at Larsen station B_South indicate a low incidence of grounded ice and the presence of filter feeders before ice-shelf disintegration (J. Gutt, unpub- lished results). The existence of a precollapse megabenthic community implicates that also meiofauna and, by extension, nematodes were present at $B \_$south before the collapse. However, due to the absence of a direct source of fresh food from the ocean surface, the fauna underneath the ice-shelves was probably impoverished in abundance and diversity, relying entirely on advected food supplied from open water by bottom currents. This agrees with the study of Azam et al. (1979), who found extremely low benthic faunal abundance underneath the Ross Ice Shelf. The depauperated nematofauna in the Larsen area could have been typically dominated by one or a few genera adapted to oligotrophic conditions, resulting in low evenness. The nematode community at station B_West, characterized by a combination of low densities, low genus richness and a high dominance of Halomonhystera, could reflect precollapse conditions. Halomonhystera was also found to be significantly higher in abundance in the deeper sediment layers, which generally contain much less organic food. Literature data do not support the idea of Halomonhystera as a typical genus for low food conditions. However, $H$. alomonhystera disjuncta is known for its high resistance to environmental stress (Vranken et al., 1989) and might be able to actively adapt to changing food conditions by trophic specialization (Van Gaever et al., 2006). 
Table 3 Features of the Larsen stations and their associated nematode communities

\begin{tabular}{lllll}
\hline & Larsen B_South & Larsen B_North & Larsen A_South & Larsen B_West \\
\hline Larsen area & Larsen B & Larsen B & Larsen A & Larsen B \\
Free of ice cover in & 1995 & 2002 & Later than 2002 & Later than 2002 \\
Nematode densities & High & Medium & Low & Low \\
Dominant genus & Microlaimus & Thalassomonhystera & Thalassomonhystera & Halomonhystera \\
Genus richness & High & Low & High & Medium \\
Evenness/average taxonomic distinctness & High & Low & High & Low \\
Pigment content & Medium & High & High & Low \\
Grain size & Medium & Medium & High & Low \\
\hline
\end{tabular}

The significantly higher densities, higher diversity and significantly different community structure at reference station B_South can be explained by the longer period free of ice cover and open to potentially increased food supply from surface phytoplankton blooms, in combination with the proximity of the open Weddell Sea as a nearby source for advected food and colonization by nematodes. Quick colonizers might have seized the opportunity to swiftly invade the new space, which became more easily available after ice retreat between 1992 and 1995. Moreover, high nematode abundance at B_South could also be related to a more recent increase in food, as Domack et al. (2005) showed very high phytoplankton concentrations in the area of B_South in 2001, i.e. shortly before the 2002 Larsen B ice shelf collapse.

The community at this station can be seen either as (1) a community at an intermediate stage of succession, in which case Microlaimus is dominant because it is the fastest and most efficient colonizer, or (2) a community at a later stage of succession, implying that it should be comparable to nematode communities in the western part of the Weddell Sea. In fact, arguments exist for both hypotheses. The genus Microlaimus is a rather important and usually dominant-subdominant genus in the eastern Weddell Sea (Vanhove et al., 1999), in the deeper parts of the South Sandwich Trench (2300-6300 m; Vanhove et al., 2004), on the Scotia Arc shelf (277-307 m; Ingels et al., 2006) and on the Weddell Sea abyssal plain (4500-5000 m; Sebastian et al., 2007). In contrast, relative abundances of Paracanthonchus, and especially of Metadesmolaimus (a usually uncommon genus for the Weddell Sea), were much higher at B_South than at any other station investigated in the Weddell Sea so far. These disparities do not necessarily implicate that the communities at B_South are different from those at any nearby Weddell Sea station. Owing to the paucity of studies on the nematofauna in the Southern Ocean, however, we were obliged to compare with stations far away from the Larsen area. The western part of the Weddell Sea is especially under-explored for this key group of the marine benthos.
Microlaimus is also known as an opportunistic genus that benefits from increased but unpredictable organic food input (Van Gaever et al., 2004, 2006). Lee et al. (2001) observed that after iceberg scouring, a Microlaimus species dominated the nematode community during the entire recolonization process, from the first day after disturbance onwards. This genus is thus considered a successful, fast and opportunistic colonizer (Van Gaever et al., 2009). The high colonization potential of Microlaimus rivals that of its close relative Molgolaimus, another opportunistic colonizer abundant under stressful conditions and in recently colonized sediments (Fonseca et al., 2006, 2007).

Densities at station B_South were higher or in the range of densities found at other locations in the Weddell, Scotia and Ross Seas (Herman \& Dahms, 1992; Vanhove et al., 1995, 2004; Fabiano \& Danovaro, 1999; Gutzmann et al., 2004; Ingels et al., 2006), whereas the inner stations were still impoverished 5 years after the Larsen B ice-shelf collapse (the same is true for the meiobenthic community on a higher taxon level: J. Gutt, unpublished results). Low food conditions must have negatively affected sub-ice nematode abundance, and it appears that density increase at the inner stations after ice-shelf disintegration has been a slow process. An increase in nematode abundance could have been either the result of (1) increased food supply and/or (2) colonization from adjacent ice-free areas. According to Stanwell-Smith \& Barnes (1997), Barnes \& Conlan (2007) and Smale \& Barnes (2008), Antarctic benthic organisms generally have slow recolonization potential, with occasional (interannual) major colonization events. Moreover, long-distance colonization by nematodes is known as a slow and gradual process, mainly occurring via passive transport by bottom currents (Boeckner et al., 2009). In their study on the recolonization potential of nematodes after an iceberg scouring event, Lee et al. (2001) showed that it took nematodes 30 days to reach control density levels inside the iceberg scour. Although the distance between control site (adjacent to the scour) and impacted site was not mentioned in their paper, it could not have been more than $5 \mathrm{~m}$, as the scour had a 
width of $10 \mathrm{~m}$. Thus, full recovery of nematode abundance occurred at a rate of 30 days for $5 \mathrm{~m}$, or $60.8 \mathrm{~m} \mathrm{yr}^{-1}$. With a distance of $70.8 \mathrm{~km}$ between the inner station B_West and the open Weddell Sea (we take station B_South as a reference again), a similar colonization speed would result in a time span of more than 1000 years before the nematode community at station B_West has fully recovered its abundance levels. Obviously, this is a very crude extrapolation and there might be other factors influencing the speed of long-distance dispersal (mortality, current direction ...). Nevertheless, it indicates that recolonization of the inner stations could be a process taking a long period of time.

Obviously, the time needed for the first colonizers to reach the inner stations is much shorter. Assuming that Larsen B_North became ice free somewhere in 2002, colonization rates can nevertheless be regarded as slow because nematode community composition at this station was still very different from the reference situation. Time needed for colonization of the inner stations seems to be in the order of magnitude of at least a decade or more. This agrees well with the projections compiled by Barnes \& Conlan (2007), that complete recovery by macrofauna after iceberg scouring (by colonization) might take tens to hundreds of years, but the time for communities to become indistinguishable in composition from undisturbed assemblages may be considerably less, around a decade. Indeed, even though we sampled the area almost 5 years after the Larsen B collapse, the communities inside the embayment were clearly not yet completely recovered from the long-term shortage of fresh food and other potential ice coverrelated restrictions. The relatively high densities at B_North, probably the first inner station that became free of shelf ice, could well be related to an input of early colonizers, or the effect of local environmental conditions. As nematode colonization mainly occurs via bottom currents, colonization speed depends on the present course of near-bottom currents in the Larsen areas. In the absence of such information, we cannot predict which of the inner stations will be colonized most rapidly.

Even though Larsen A became free of ice cover in 1995, station A_South was still covered by shelf ice in 2002 and in 2007 its community composition was still very similar to that of station B_North. We conclude that the inner stations were not yet (or, in the case of B_North, only to a small extent) colonized by nematodes from the open Weddell Sea. As a result, differences between these stations should be the result of changes in the local genus pool in relation to environmental conditions. In this sense, the considerable difference in densities between B_North and A_South, two otherwise very comparable stations, could also be explained by differences in sediment composition, as muddy sediments (B_North) are known to yield the highest nematode densities and coarser sediments (A_South: lower pellite, but higher sand fraction) are considered less favorable for the typically interstitial nematodes (Tietjen, 1977; Heip et al., 1985; Fabiano \& Danovaro, 1999; Brandt et al., 2007). J. Gutt (unpublished results) recorded high near-bottom current activity at A_South. All stations considered in our study are classified as muddy sediments (A_South: silt loam; other stations: silty clay loam).

The high genus richness and high evenness at station A_South seems remarkable for an inner station. Again, the striking contrast with B_North, characterized by very low diversity, could be related to a combination of environmental factors. A_South has a significantly higher fraction of fresh chlorophyll $a$, which might support a more diversified community. Furthermore, nematode communities tend to be more diverse in coarse, sandy environments with no shortage of available interstitia (Heip et al., 1985). Dominance in nematode assemblages is generally known to be high in muds and lower in sediments with a higher sand fraction (Tietjen, 1977; Heip et al., 1985), and an inverse relationship between diversity and silt-clay has been suggested (Tietjen, 1977). On the other hand, diversity and granulometry are not always connected (Boucher \& Lambshead, 1995). Also note the large error bars both for diversity (Fig. 3) and granulometry (especially deeper sediment layers) (Fig. 7), indicating considerable within-station variation.

The differences in densities and diversity between B_North and A_South contrast sharply with our community results. These stations appear to be only comparable in the high pigment content of the sediment and their nearby geographical position. Faunal exchange between both stations could explain the similarities in community composition and the recent availability of fresh food could have promoted the dominance of Thalassomonhystera here, an opportunistic genus occurring e.g. under limiting conditions, such as near hydrothermal vents (Copley et al., 2007). As an opportunist, it could have taken advantage of the fresh food input to become more abundant, outcompeting several other taxa. The very high dominance of Thalassomonhystera in the upper cm of station B_West, where almost all pigments were concentrated, agrees with this idea. On the other hand, the genus was more abundant at the oligotrophic EUMELI site (Cape Verde Abyssal Plain) than at a eutrophic Porcupine Abyssal Plain station (Vanreusel et al., 1995; Sebastian et al., 2007). Together, the monhysterids Thalassomonhystera and Halomonhystera accounted for approximately $80 \%$ of the commu- 
nities at B_West and B_North, the stations with the lowest mean grain size (10.03 and $19.47 \mu \mathrm{m}$ on average) and lowest percentage of sand $(0.66 \%$ and $3.90 \%$ on average). This agrees with the inverse correlation between the occurrence of Monhysteridae and (1) sand fraction and (2) mean particle size, as observed by Vanhove et al. (2004).

The food-rich environment at stations B_North and A_South contrasts sharply with the oligotrophic conditions at station B_West, and is most likely the result of a recent phytoplankton bloom in the area. The close proximity of land and an increased run-off of meltwater from its glaciers (e.g. Drygalski Glacier) create excellent conditions for the development of large blooms at both former stations in summer. Glaciers in this area accelerated in flow speed (Rott et al., 2002; Scambos et al., 2004) and rate of retreat (Cook et al., 2005) as a result of warming and the Larsen ice-shelf collapse events. Meltwater provides a replenishment of macronutrients for the phytoplankton in the area (Dierssen et al., 2002; Clarke et al., 2007), and the establishment of a stable surface layer and a shallow mixed layer are essential for phytoplankton bloom development (Mitchell \& HolmHansen, 1991; Clarke et al., 2007). On the other hand, sediment discharge from glaciers reduces light penetration and thus limits primary production (Dierssen et al., 2002), and reduced surface water salinity also affects food quality of the phytoplankton community, i.e. by a shift from diatoms to cryptophytes (Moline et al., 2004).

Although differences in food supply, e.g. between stations A_South and B_West, could have been evident in nematode trophic composition, this is not the case here. Both Halomonhystera and Thalassomonhystera are characterized as non-selective deposit feeders. This trophic group is typical for muddy sediments, whereas sandy sediments are usually dominated by epistratum feeders (Heip et al., 1985). On the other hand, this is clearly not the case at station B_South, which is characterized by a dominance of epistratum feeders, but also a relatively low mean grain size. The high abundance of epistratum feeders at this station was mainly attributed to the dominance of Microlaimus, whose high abundance here might be related to other issues (cf. supra).

The significantly lower average values of taxonomic distinctness $\left(\Delta^{*}\right)$ at B_North (and B_West), and significantly higher variation in taxonomic distinctness $\left(\Lambda^{+}\right)$ for the entire community at B_North indicate both a low taxonomic spread in the nematode community at this station (i.e. relatively more similar taxa), and a high unevenness in its phylogenetic structure. This is related to an increase in abundance of Thalassomonhystera, which outcompeted other, more sensitive genera. Low diversity at B_North could be explained by a negative correlation between evenness and a combination of abundant food and fine sediment (Tietjen, 1977; Sebastian et al., 2007). A similar connection between a negative correlation of taxonomic distinctness and variation in taxonomic distinctness, and a decrease in diversity, was observed by Warwick et al. (2002).

Although some differences between stations are explained by differences in environmental conditions, our BIO-ENV analysis showed no perfect match between environmental variables and the observed biological patterns. In our opinion, these patterns can only be explained by a combination of historical (length of icefree period), geographical (position in the Larsen area) and present-day environmental (food supply, sediment granulometry) aspects.

As nematodes are considered an essential and basic component of the benthic fauna, their mode of response could be indicative for that of the whole benthic community. However, macro- and megabenthic response is not entirely the same as that of the nematode communities, both in terms of abundance and diversity (J. Gutt, unpublished results). This indicates that different ecological units of the benthos have a different response to ice-shelf collapse and subsequent changes in environmental conditions.

\section{Conclusions}

This study is the first to investigate the benthic communities in the newly ice-free Larsen A and B regions. The nematofauna in these areas has been strongly influenced by the presence and sudden removal of the ice cover, although its response is not entirely identical to that of the macro- and megafauna. Sub-ice nematode communities in the Larsen area were probably impoverished in abundance and diversity. Our results indicate that after ice-shelf collapse, the response of the communities on a local scale, in relation to locally increased food availability, is faster than the response due to recolonization of the inner stations from the open Weddell Sea, which is believed to be a process taking a long period of time. The station closest to the open Weddell Sea and ice-free for at least 12 years was comparable with other Antarctic stations in terms of nematode abundance and community composition, whereas stations located deeper inside the Larsen embayments, which have been ice-free for only a few years, are not yet or only slightly influenced by new colonizers. In general, our study reveals that the collapse of ice shelves covering Larsen A and B initially has a positive effect on the nematode fauna of the continental shelf in the area, both in terms of abundance and diversity. 


\section{Acknowledgements}

The authors wish to thank Bart Beuselinck, Dirk Van Gansbeke and Daniëlle Schram for their laboratory analyses on the nematofauna and sediment properties. The officers and crew of the research vessel Polarstern are acknowledged for their valuable support in MUC deployment on board. Special thanks go to the subject editor and two anonymous reviewers for their constructive remarks. This research was conducted within the framework of the BIANZO II project, financed by the Belgian Science Policy (Scientific Research Program on Antarctica). Support by the Deutsche Forschungsgemeinschaft (DFG: project RO 3004/2-1) is gratefully acknowledged by A. Rose.

\section{References}

Arntz WE, Brey T, Gallardo VA (1994) Antarctic zoobenthos. Oceanography and Marine Biology: An Annual Review, 32, 241-304.

Arrigo KR, van Dijken GL, Ainley DG, Fahnestock MA, Markus T (2002) Ecological impact of a large Antarctic iceberg. Geophysical Research Letters, 29, 1104.

Azam F, Beers JR, Campbell L, Carlucci AF, Holm-Hansen O, Reid FMH, Karl DM (1979) Occurrence and metabolic activity of organisms under the Ross Ice Shelf, Antarctica, at station J9. Science, 203, 451-453.

Barnes DKA, Conlan KE (2007) Disturbance, colonization and development of Antarctic benthic communities. Philosophical Transactions of the Royal Society B $362,11-38$.

Barnes DKA, Peck LS (2008) Vulnerability of Antarctic shelf biodiversity to predicted regional warming. Climate Research, 37, 149-163.

Bathmann U, Fischer G, Müller PJ, Gerdes D (1991) Short-term variation in particulate matter sedimentation off Kapp Norvegia, Weddell Sea, Antarctica: relation to water mass advection, ice cover, plankton biomass and feeding activity. Polar Biology, 11, 185-195.

Boeckner MJ, Sharma J, Proctor HC (2009) Revisiting the meiofauna paradox: dispersal and colonization of nematodes and other meiofaunal organisms in low- and highenergy environments. Hydrobiologia, 624, 91-106

Boucher G, Lambshead PJD (1995) Ecological biodiversity of marine nematodes in samples from temperate, tropical, and deep-sea regions. Conservation Biology, 9 1594-1604.

Brandt A, De Broyer C, De mesel I et al. (2007) The biodiversity of the deep Southern Ocean benthos. Philosophical Transactions of the Royal Society B, 362, 39-66.

Chapman WL, Walsh JE (2007) A synthesis of Antarctic temperatures. Journal of Climate, 20, 4096-4117

Clarke A, Murphy EJ, Meredith MP, King JC, Peck LS, Barnes DKA, Smith RC (2007) Climate change and the marine ecosystem of the western Antarctic Peninsula. Philosophical Transactions of the Royal Society B, 362, 149-166.

Clarke KR, Gorley RN (2001) PRIMER v5: User Manual/Tutorial. PRIMER-E, Plymouth.

Clarke KR, Warwick RM (2001) Change in Marine Communities: An Approach to Statistical Analysis and Interpretation. PRIMER-E, Plymouth.

Cook AJ, Fox AJ, Vaughan DG, Ferrigno JG (2005) Retreating glacier fronts on the Antarctic Peninsula over the past half-century. Science, 308, 541-544.

Copley JTP, Flint HC, Ferrero TJ et al. (2007) Diversity of meiofauna and free-living nematodes in hydrothermal vent mussel beds on the northern and southern Eas Pacific Rise. Journal of the Marine Biological Association of the United Kingdom, 87, 1141-1152.

Dierssen HM, Smith RC, Vernet M (2002) Glacial meltwater dynamics in coastal waters west of the Antarctica peninsula. Proceedings of the National Academy of Sciences, 99, 1790-1795.

Domack E, Duran D, Leventer A et al. (2005) Stability of the Larsen B ice shelf on the Antarctic Peninsula during the Holocene epoch. Nature, 436, 681-685.

Dufrêne M, Legendre P (1997) Species assemblages and indicator species: the need for a flexible asymmetrical approach. Ecological Monographs, 67, 356-366.

Fabiano M, Danovaro R (1999) Meiofauna distribution and mesoscale variability in two sites of the Ross Sea (Antarctica) with contrasting food supply. Polar Biology, 22, 115-123.

Fahrbach E, Meyer R, Rohardt G, Schröder M, Woodgate RA (1998) Gradual warming of the Weddell Sea deep and bottom water. Filchner-Ronne Ice-Shelf Program, Report no. 12, Alfred-Wegener-Institut, Bremerhaven, Germany, pp. 24-34.
Fonseca G, Muthumbi AW, Vanreusel A (2007) Species richness of the genus Molgolaimus (Nematoda) from local to ocean scale along continental slopes. Marine Ecology, 28, 446-459.

Fonseca G, Vanreusel A, Decraemer W (2006) Taxonomy and biogeography of Molgolaimus Ditlevsen, 1921 (Nematoda: Chromadoria) with reference to the origins of deep sea nematodes. Antarctic Science, 18, 23-50.

Gutt J (2001) On the direct impact of ice on marine benthic communities, a review. Polar Biology, 24, 553-564.

Gutt J, Piepenburg D (2003) Scale dependent impact on diversity of Antarctic benthos caused by grounding of icebergs. Marine Ecology Progress Series, 253, 77-83.

Gutzmann E, Martinez Arbizu P, Rose A, Veit-Köhler G (2004) Meiofauna communities along an abyssal depth gradient in the Drake Passage. Deep-Sea Research II, 51, $1617-1628$

Hain S, Melles M (1994) Evidence for a marine molluscan fauna beneath ice shelves in the Lazarev and Weddell Seas, Antarctica, from shells of Adamussium colbecki and Nacella (patinigera) cf. concinna. Antarctic Science, 6, 29-36.

Heip C, Vincx M, Vranken G (1985) The ecology of marine nematodes. Oceanography and Marine Biology Annual Review, 23, 399-489.

Herman RL, Dahms HU (1992) Meiofauna communities along a depth transect of Halley Bay (Weddell Sea - Antarctica). Polar Biology, 12, 313-320.

Hill MO (1973) Diversity and evenness: a unifying notation and its consequences. Ecology, 54, 427-432.

Hurlbert SH (1971) The non-concept of species diversity: a critique and alternative parameters. Ecology, 52, 577-586.

Ingels J, Vanhove S, De Mesel I, Vanreusel A (2006) The biodiversity and biogeography of the free-living nematode genera Desmodora and Desmodorella (family Desmodoridae) at both sides of the Scotia Arc. Polar Biology, 29, 936-949.

Johst K, Gutt J, Wissel C, Grimm V (2006) Diversity and disturbances in the Antarctic megabenthos: feasible versus theoretical disturbance ranges. Ecosystems, 9, 11451155

King JC, Turner J, Marshall GJ, Conolley WM, Lachlan-Cope TA (2003) Antarctic Peninsula climate variability and its causes as revealed by analysis of instrumental records. Antarctic Research Series, 79, 17-30.

Lambshead PJD (2004) Marine nematode biodiversity. In: Nematology, Advances and Perspectives (eds Chen ZX, Chen SY, Dickson DW), pp. 436-467. ACSE-TUP Book Series, Phoenix.

Lee HJ, Vanhove S, Peck LS, Vincx M (2001) Recolonisation of meiofauna after catastrophic iceberg scouring in shallow Antarctic sediments. Polar Biology, 24, 918-925.

Lipps JH, Ronan TE, DeLaca TE (1979) Life below the Ross Ice Shelf. Science, 203, 447449.

McCune B, Mefford MJ (1999) PC-ORD. Multivariate Analysis of Ecological Data. Version 4.32. MjM Software, Gleneden Beach, OR, USA

Mitchell BG, Holm-Hansen O (1991) Bio-optical properties of Antarctic Peninsula waters: differentiation from temperate ocean models. Deep-Sea Research, 38, 1009_ 1028.

Moline MA, Claustre H, Frazer TK, Schofield O, Vernet M (2004) Alteration of the food web along the Antarctic Peninsula in response to a regional warming trend. Global Change Biology, 10, 1973-1980.

Oliver JS, Watson DJ, O'Connor EF, Dayton PK (1976) Benthic communities of McMurdo Sound. Antarctic Journal of the United States, 11, 58-59.

Peck LS, Brockington S, Vanhove S, Beghyn M (1999) Community recovery following catastrophic iceberg impacts in a soft-sediment shallow-water site at Signy Island, Antarctica. Marine Ecology Progress Series, 186, 1-8.

Post AL, Hemer MA, O'Brien PE, Roberts D, Craven M (2007) History of benthic colonization beneath the Amery ice shelf, East Antarctica. Marine Ecology Progres Series, 344, 29-37.

Riddle MJ, Craven M, Goldsworthy PM, Carsey F (2007) A diverse benthic assemblage $100 \mathrm{~km}$ from open water under the Amery Ice Shelf, Antarctica. Paleoceanography, 22, PA1204.

Robertson R, Visbeck M, Gordon AL, Fahrbach E (2002) Long-term temperature trends in the deep waters of the Weddell Sea. Deep-Sea Research II, 49, 4791-4806.

Rott H, Rack W, Skvarca P, De Angelis H (2002) Northern Larsen Ice Shelf, Antarctica: further retreat after collapse. Annals of Glaciology, 34, 277-282.

Scambos TA, Bohlander JA, Shuman CA, Skvarca P (2004) Glacier acceleration and thinning after ice shelf collapse in the Larsen B embayment, Antarctica. Geophysical Research Letters, 31, L18402.

Scambos TA, Fahnestock M, Bohlander J (2000) The link between climate warming and break-up of ice shelves in the Antarctic Peninsula. Journal of Glaciology, 46, 516-530. 
Schratzberger M, Lampadariou N, Somerfield PJ, Vandepitte L, Vanden Berghe E (2009) The impact of seabed disturbance on nematode communities: linking field and laboratory observations. Marine Biology, 156, 709-724.

Sebastian S, Raes M, De Mesel I, Vanreusel A (2007) Comparison of the nematode fauna from the Weddell Sea Abyssal Plain with two North Atlantic abyssal sites. Deep-Sea Research II, 54, 1727-1736.

Seinhorst JW (1959) A rapid method for the transfer of nematodes from fixative to unhydrous glycerine. Nematologica, 4, 67-69.

Smale DA, Barnes DKA (2008) Likely responses of the Antarctic benthos to climaterelated changes in physical disturbance during the 21st century, based primarily on evidence from the West Antarctic Peninsula region. Ecography, 31, 289-305.

Solomon S, Qin D, Manning M et al. (2007) Climate Change 2007: the Physical Science Basis. Contribution of Working Group I to the Fourth assessment report of the Intergovernmental Panel on Climate Change. Cambridge University Press, Cambridge.

Stanwell-Smith D, Barnes DKA (1997) Benthic community development in Antarctica: recruitment and growth on settlement panels at Signy Island. Journal of Experimental Marine Biology and Ecology, 212, 61-79.

Tietjen JH (1977) Population distribution and structure of the free-living nematodes of Long Island Sound. Marine Biology, 43, 123-136.

Van Gaever S, Galéron J, Sibuet M, Vanreusel A (2009) Unravelling deep-sea habitat heterogeneity based on meiofauna communities in the Gulf of Guinea. Deep-Sea Research II, 56, 2259-2269.

Van Gaever S, Moodley L, de Beer D, Vanreusel A (2006) Meiobenthos at the Arctic Håkon Mosby Mud Volcano with a parental caring nematode thriving in sulphiderich sediments. Marine Ecology Progress Series, 321, 143-155.

Van Gaever S, Vanreusel A, Hughes JA, Bett B, Kiriakoulakis K (2004) The macro- and micro-scale patchiness of meiobenthos associated with the Darwin Mounds (northeast Atlantic). Journal of the Marine Biological Association of the United Kingdom, 84, 547-556.

Vanhove S, Arntz W, Vincx M (1999) Comparative study of the nematode communities on the southeastern Weddell Sea shelf and slope (Antarctica). Marine Ecology Progress Series, 181, 237-256.

Vanhove S, Beghyn M, Van Gansbeke D, Bullough LW, Vincx M (2000) A seasonally varying biotope at Signy Island, Antarctic: implications for meiofaunal structure. Marine Ecology Progress Series, 202, 13-25.

Vanhove S, Vermeeren H, Vanreusel A (2004) Meiofauna towards the South Sandwich Trench (750-6300 m), focus on nematodes. Deep-Sea Research II, 51, 1665-1687.
Vanhove S, Wittoeck J, Desmet G et al. (1995) Deep-sea meiofauna communities in Antarctica: structural analysis and relation with the environment. Marine Ecology Progress Series, 127, 65-76.

Vanreusel A, Clough L, Jacobsen K et al. (2000) Meiobenthos of the central Arctic Ocean with special emphasis on the nematode community structure. Deep-Sea Research I, 47, 1855-1879.

Vanreusel A, Vincx M, Bett BJ, Rice AL (1995) Nematode biomass spectra at two abyssal sites in the NE Atlantic with a contrasting food supply. Internationale Revue der gesamte Hydrobiologie, 80, 287-296.

Vaughan DG, Doake CSM (1996) Recent atmospheric warming and retreat of ice shelves on the Antarctic Peninsula. Nature, 379, 328-331.

Vaughan DG, Marshall GJ, Connolley WM et al. (2003) Recent rapid regional climate warming on the Antarctic Peninsula. Climatic Change, 60, 243-274.

Vincx M (1996) Meiofauna in marine and freshwater sediments. In: Methods for the Examination of Organismal Diversity in Soils and Sediments (ed. Hall GS), pp 187-195. Cab International, Cambridge.

Vincx M, Bett BJ, Dinet A et al. (1994) Meiobenthos of the deep Northeast Atlantic Advances in Marine Biology, 30, 2-79.

Vincx M, Heip C (1991) The use of meiobenthos in pollution monitoring studies: a review. ICES, 16, 50-67.

Vranken G, Tiré C, Heip C (1989) Effect of temperature and food on hexavalent chromium toxicity to the marine nematode Monhystera disjuncta. Marine Environmental Research, 27, 127-136.

Warwick RM, Ashman CM, Brown AR et al. (2002) Inter-annual changes in the biodiversity and community structure of the macrobenthos in Tees Bay and the Tees estuary, UK, associated with local and regional environmental events. Marine Ecology Progress Series, 234, 1-13.

Warwick RM, Clarke KR (2001) Practical measures of marine biodiversity based on relatedness of species. Oceanography and Marine Biology: An Annual Review, 39, 207231.

Warwick RM, Platt HM, Somerfield PJ (1998) Free-Living Marine Nematodes Part III Monhysterids: Pictorial Key to World Genera and Notes for the Identification of British Species. Synopses of the British fauna (new series), 53. Field Studies Council, Shrewsbury, UK.

Wieser W (1953) Die Beziehung zwischen Mundhöhlengestalt, Ernährungsweise und Vorkommen bei freilebenden marinen Nematoden. Eine ökologisch-morphologische Studie. Arkiv för Zoologi, 4, 439-483. 